\title{
THE JAPANESE TOBACCO CULTURE IN THE EDO PERIOD (1603-1867)
}

Tobacco was introduced into Japan during the latter half of the 16th century. It was a new habit brought in as part of the external trade called the namban trade (Japan's trade mainly with Portugal in the latter 16th and early 17th centuries).

After its initial contact with the Portuguese at Tanegashima Island in 1543 and the arrival of the first Portuguese commercial vessel in 1550 Japan began to trade actively with the European nations including Spain, Holland and England. Many new artefacts and new cultural forms, such as Catholicism, typography, guns, sugar, potatoes and tobacco smoking were introduced into Japan, along with many others, during the era of the namban trade.

As Christianity started to spread throughout the country the Europeans came to be seen as an obstacle for the rulers seeking unification of the nation. The Tokugawa Shogunate issued the Edicts of Seclusion prohibiting maritime trade and the reception of foreign ships from nations other than a few exceptions including Holland and China. With Holland commercial trade was restricted to the extremely small man-made island of Deshima in the bay of Nagasaki from 1641, after an initial period of 32 years in Hirado. The Edo period was an era in which a characteristically unique culture in world history was developed and which lasted for approximately 260 years until the Meiji Restoration of 1868.

With this background many of the smoking utensils such as kiseru (traditional metal pipes), tabako-bon (tobacco trays), and tabako-ire (tobacco pouches), that were developed early in the Edo period, made substantial improvements.

\section{The Tobacco culture in the Edo period}

When tobacco was first introduced into Japan the people of Japan did not have a custom of setting fire to dried plant leaves and inhaling the smoke, even though they had a custom of fuming incense and enjoying the scent. Toward the end of the 16th century when tobacco was introduced the era of endemic warfare was over in Japan but public security was still unstable. Groups of rogues called kabuki-mono used the new habit brought in from foreign countries as their symbol (fig. 1). Rogues made their servants carry kiseru that were far longer than necessary for practical usage, and carried iron kiseru referred to as "kiseru for fighting," that were more fitting as a weapon than to be used for smoking. (Commoners in the Edo period were not allowed to carry swords.) The rogues stirred up law and order in the towns. The Edo Shogunate tried to control them and prohibited people from smoking. In 1612

Fig.

Mesamasshi Kusa, 1815, private edition by Seichutei Shukushin, Tobacco \& Salt Museum collection, Tokyo. a nationwide order was enforced to prohibit smoking, trading and even cultivating tobacco. Similar prohibitions were issued year after year, with slight differences in content, throughout the Genroku era (1688-1704). Viewed from a different perspective the ordinary people never gave up the 


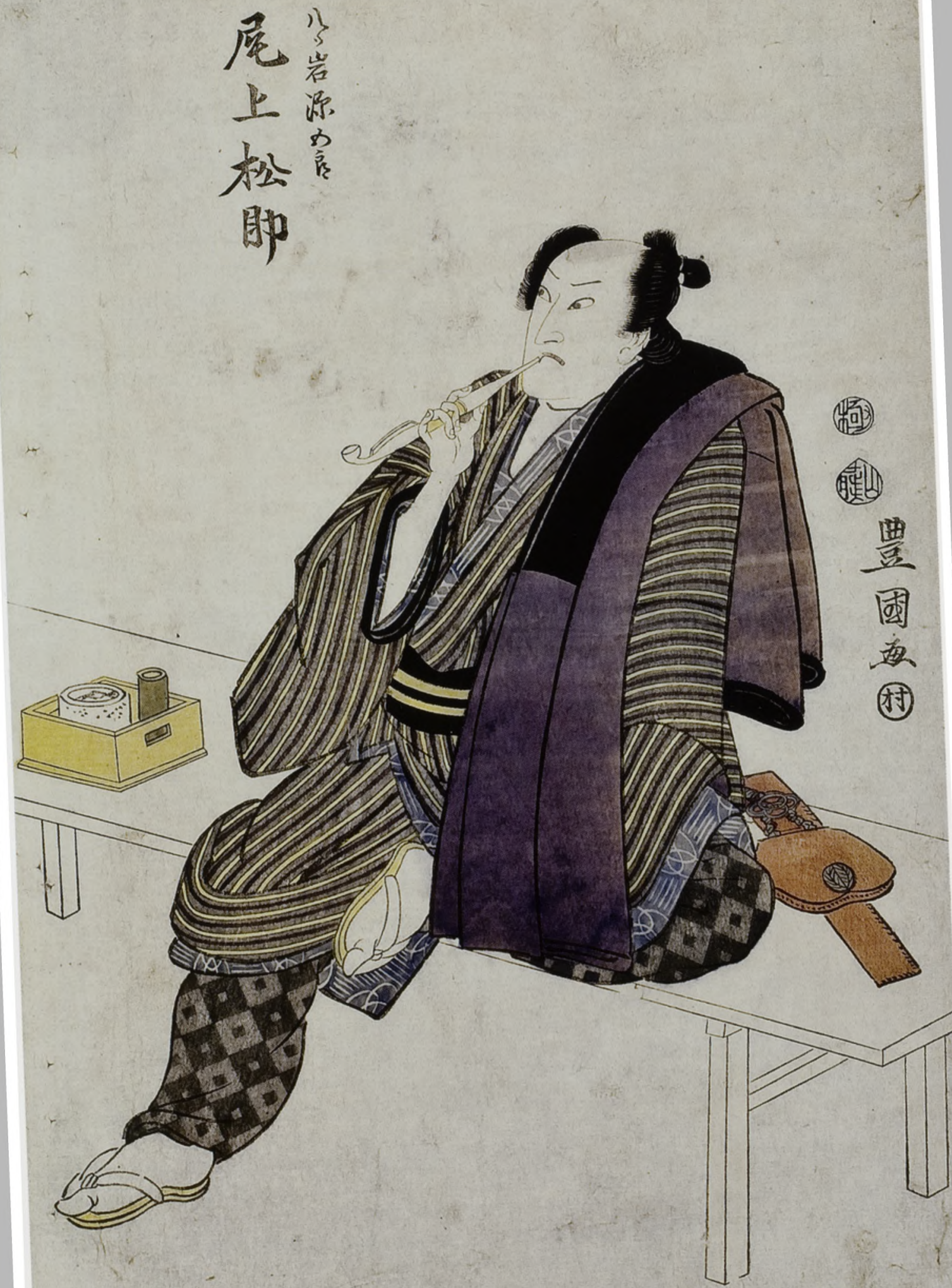


custom of smoking in spite of the series of prohibitions, and the custom continued to spread while undergoing significant changes. Tobacco was given a new role as a tool for offering hospitality when welcoming a guest, and for

Fig. 2 Utagawa Toyokuni, "Ogamisyousuke no Yatsuiwa Gengoro", ca. 1812, öban, publisher: Murataya jirobeh, Tokyo. helping people communicate more smoothly. Tobacco trays accompanied with kiseru were placed in the guest room, and rules of etiquette and formality were developed in which the master of the household offered tobacco first to his guest and the guest had to show his gratitude after smoking.

Visitors were first welcomed into the guest room where a tobacco tray was prepared. When the master appeared and just as conversation began to flow, the master would say to the guest: "Help yourself to some tobacco." The guest would reply: "After you, master," and decline the offer at least two or three times. The master would then remove the tsuba, a protective shell, from the kiseru, wipe it with his paper napkin and offer it to the guest saying: "Your turn now." The guest would then receive the kiseru, take a couple of puffs, and praise the taste. When he had finished smoking, he attached the tsuba back onto the kiseru and placed it in front of him, wiping it with his own paper napkin before leaving, and returning it to the tobacco tray. The master would then say, "Please, don't worry about it."

Although this type of formality was not passed down exactly in this way, the master's hospitality towards the guest and the guest's modesty and care towards the master, as seen in this depiction, became the root of later etiquette and was inherited as a fundamental element of the tobacco culture which was formed during the Edo period.

During this period tobacco took root as a joy and pleasure for mature people; something that soothed their mind and brought a moment of enrichment to their daily life. A unique culture was formed involving tobacco smoking, which was most noteworthy during the Edo period (fig. 2).

\section{Origins of smoking utensils in Japan}

The classic Japanese kiseru (a metal pipe with a long stem and a small bowl), which remained in use until the early 20 th century, is thought to have been derived from European metal pipes.

In many cases smoking utensils other than kiseru were simply adapted from previously existing articles originally employed for other purposes. For example, Edo period tobacco pouches could trace their ancestry back to pouch forms for flint-and-steel that were already part of daily life. The first tobacco trays were apparently no more than recycled versions of trays for incense-burning implements.

\section{Kiseru and Japanese fine shred tobacco}

The oldest kiseru were long and their bowls were much larger when compared with later bowl dimensions (fig. 3). Larger bowls were needed for coarsely shredded tobacco. As time went by the kiseru bowl of the Edo period became smaller, and the kiseru itself became more compact.

The major reason for these changes is considered to be the improvements made in the tobacco shredding process. The cut tobacco leaves during the Edo period were reduced down to approximately 0.1 millimeter in width and about 80 millimeters in length, thinner than a hair and as fine as silk thread. They were found nowhere else in the world (fig. 4 ). ${ }^{\text {D }}$ Brill.come4/26/2023 11:10:21AM 
Fig. 3

Early kiseru with large bowl and long stem, bowl and mouthpiece (brass), stem (bamboo with lacquer), $44.4 \mathrm{~cm}$., early i7th c., Tobacco \& Salt Museum collection, Tokyo.
The basic form of the kiseru, with a metal bowl and a metal mouthpiece linked to a bamboo stem, was dominant in the East Asia region. More expensive, solid metal kiseru were also seen. As the technique of tobacco shredding became further refined, this resulted in a reduction of the dimensions of the bowl because of the easier charge of tobacco. Thus, the Japanese kiseru changed its shape, with a smaller bowl and a shorter stem, for portability (fig. 5).

\section{Smoking utensils as accessories}

Once outdoor smoking was permitted in the Edo period tobacco became a necessity as an important means of soothing fatigue while on a journey and tobacco pouches thus became an essential requisite for traveling. While the tobacco pouch served a practical purpose, it was also deemed an important accessory.

Men of the samurai class were permitted to carry a long sword and a short sword under their sash belt until the end of Edo period. When peace prevailed throughout the country and they were free from the affairs of war after the first quarter of the 17th century, the two swords became more important as accessories for the men of the samurai class.

Commoners, on the other hand, not being permitted to carry swords, did not have any accessory to wear on their kimono. These people were naturally
Fig. 4 Japanese fine shred tobacco for kiseru.

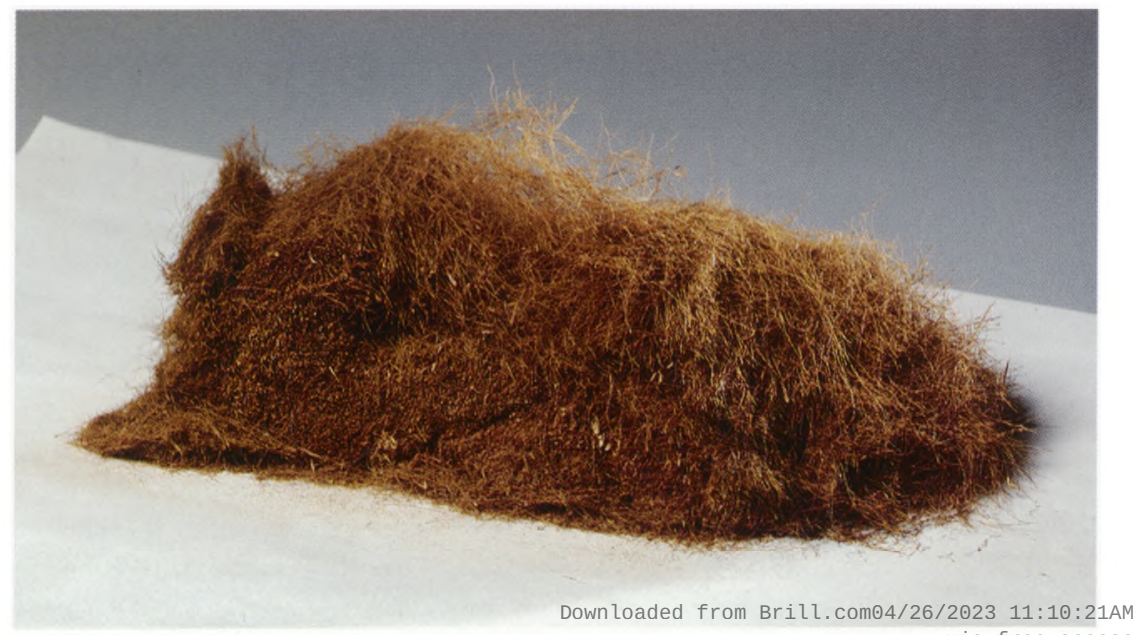


Fig. 5

Kiseru with a small bowl and a short stem, bowl and mouthpiece (iron, gold), engraving by Kano Natsuo, stem (bamboo with lacquer), $20.2 \mathrm{~cm}$., 19th c., Tobacco \& Salt Museum collection, Tokyo. attracted to tobacco pouches, not only as a tobacco container, but also to show their good taste and to accentuate their attire. They developed the tobacco pouch into an accessory that was crafted artistically and creatively. The shogunate in the Edo period warned the general population not to use luxury goods and insisted on thrift and austerity. The shogunate was displeased with the ways in which the general population enjoyed luxurious goods, and made particular mention of tobacco pouches in the luxury prohibition orders that were quite frequently issued. For example, in the Prohibition issued in 1704, during the Genroku era the use of gold and silver on tobacco pouches was prohibited.

This of course means that numerous tobacco pouches were produced at the time using gold, silver and other costly materials. The general population of the Edo period became increasingly affluent after the Genroku era (16881703), and people were clever enough to hide behind the practical nature of their tobacco pouches and to devise many ways to enhance the value of a tobacco pouch as an accessory, evading the prohibition orders.

Even tobacco pouches that appeared simple and ordinary were sometimes lined with expensive calico fabric imported from India. Gold and silver were used in tiny proportions on the metal parts of the pouch, netsuke and kiseru case in a subtle way so that no one would notice without looking closely. Some commoners commissioned skilled craftsmen to carve sophisticated designs on these metallic parts.

Behind the restrictions imposed by the shogunate, the general population competed with each other to create a highly refined sense of aesthetics using the familiar accessory of the tobacco pouch. The netsuke, which was developed as a sash hanger at this time, attracted the attention of Western visitors after the Meiji period (1868-1911), and became a valuable collector's item. It was a component for hanging a tobacco pouch or other bag onto the obi (sash belt).

Looking at the tobacco pouches of this time we find many that use costly, precious materials such as calico, velvet and other imported textiles, and cuoi d'or leather from Holland that was originally used for interior decoration in Europe. They were typical accessories of the general population during the Edo period (fig. 6 ).

The situation was similar with kiseru. Whilst they were a practical tool for smoking finely shredded tobacco, they were also decorated with exquisitely 


\section{8}

Fig. 6

Imported black leather tobacco pouch, netsuke (ivory), chain (iron), buckle (silver, alloy of copper and gold), $14.3 \mathrm{~cm}$ (width of the pouch), ca. 19th c., Tobacco \& Salt Museum collection, Tokyo.

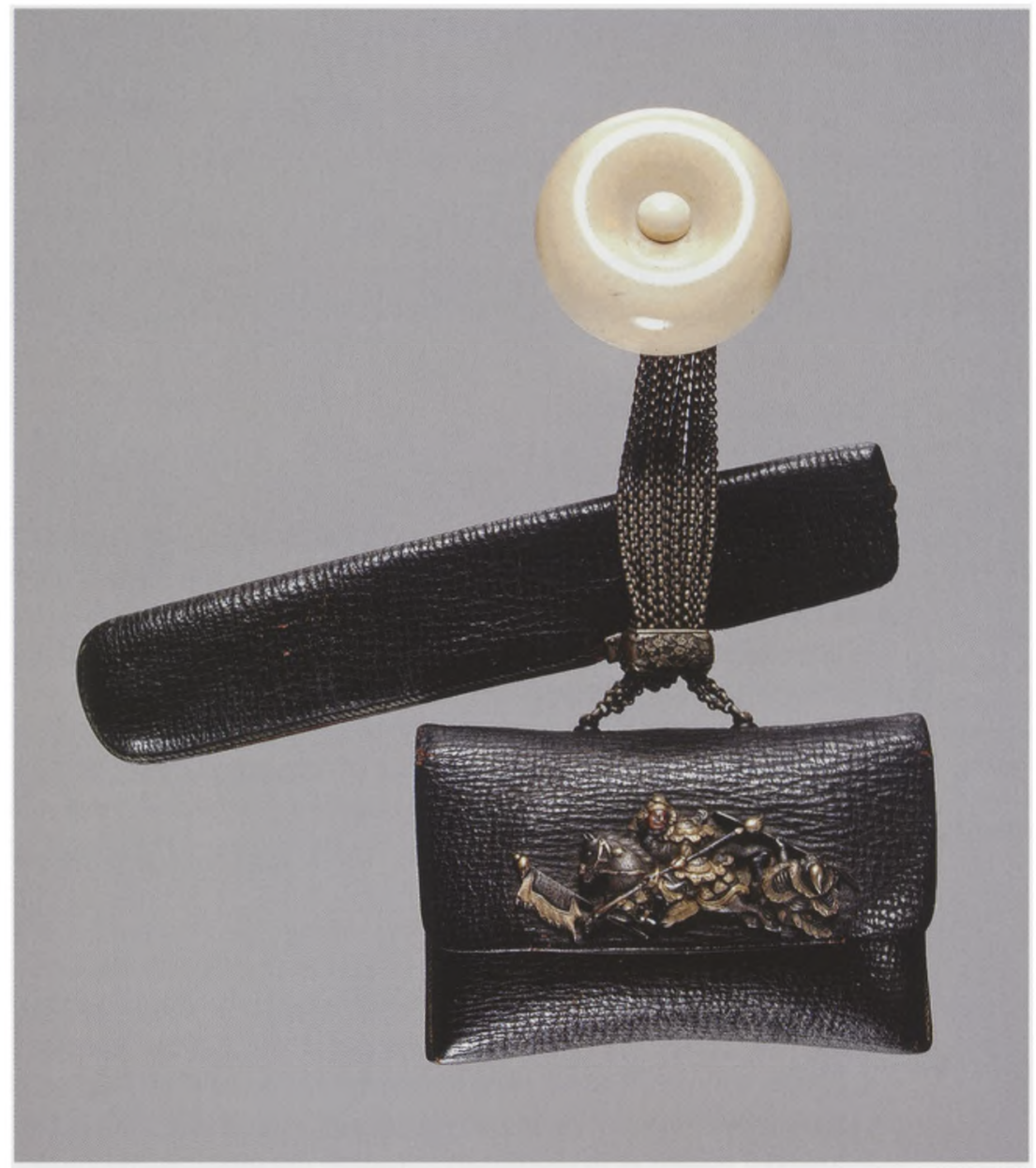

carved or inlayed metal parts, accentuated with gold and silver, and adorned with many crest patterns and designs using an alloy developed uniquely in Japan called shibuichi (an alloy of copper and silver in a ratio of $4: 1$ ) as well as pure copper (fig. 7).

The smoking utensils which developed during the Edo period, with their practical and artistic nature, matured further during the Meiji reign (18681911). The restrictions imposed by the shogunate were lifted, and craftsmen specialized in sword decoration, who had lost their jobs after the issue of a decree banning the wearing of swords, became engaged in the production of tobacco pouches. Although numerous distinguished utensils for smoking were created during the Meiji period on the foundation cultivated in the Edo period, the culture of traditional Japanese smoking utensils declined in the years after the Taisho reign (1912-1925), when Western-style clothing and cigarettes became popular.

By examining these smoking utensils we can find interesting differences in the form and materials used that relate to the owner's social class and occupation. They also illustrate the advanced skills of the Japanese craftsmen and the distinctive features of the Japanese tobacco culture in the Edo period. 
Fig. 7

Various superior kiseru of the Edo period, Tobacco \& Salt Museum collection, Tokyo.

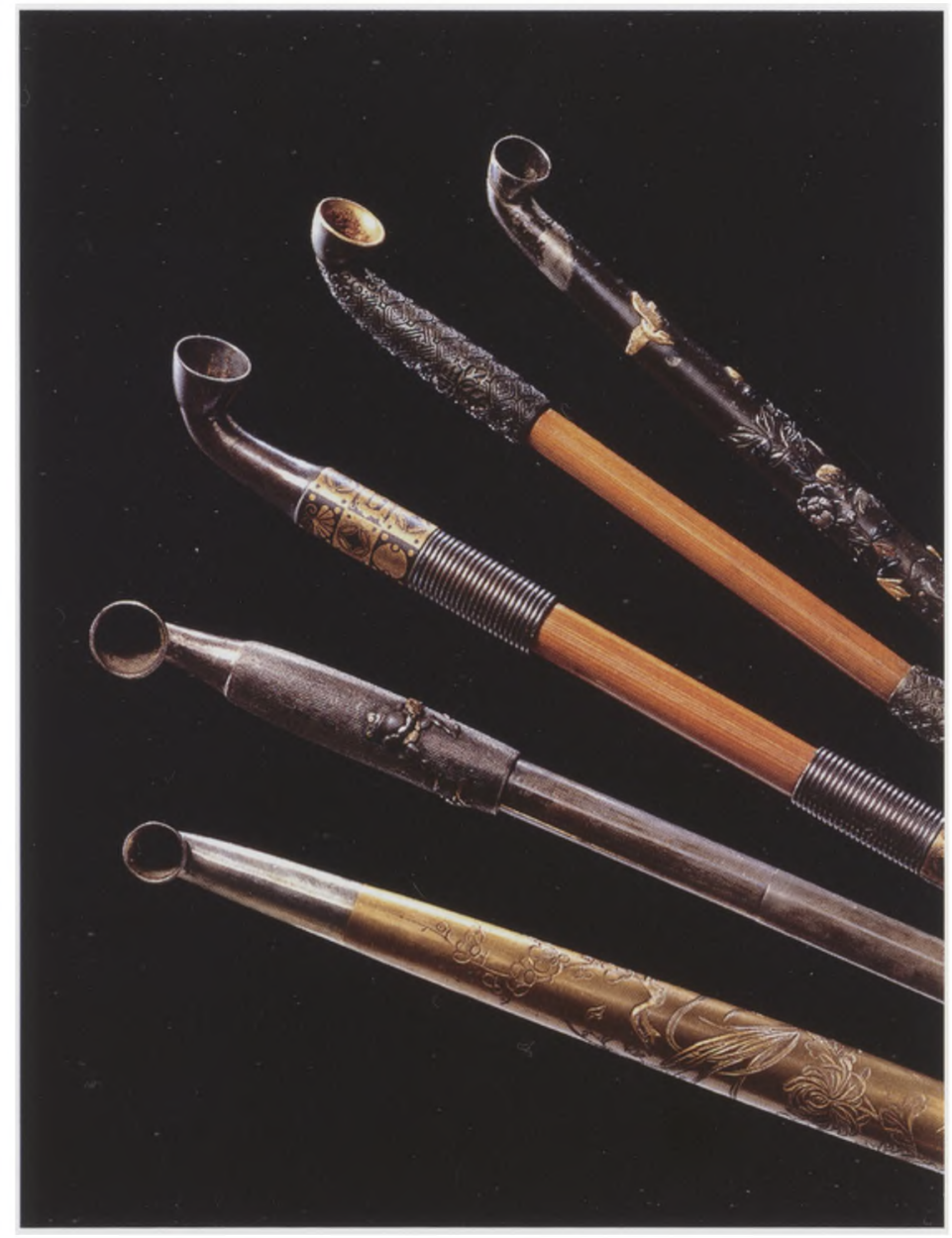

- Masayuki Handa is the Chief Curator and Director of the Curatorial Dept. of the Tobacco and Salt Museum in Tokyo. He has been working at the museum since 1978 as curator for the collection, researching the history of industrial technology, and the cultural history of tobacco and salt. He is a member of the Academie Internationale de la Pipe, Executive Director of the Japanese Association of Museums, and the Vice Chair of the ICOM-Japan.

\section{Bibliography}

Masayuki Handa, Japan, in: Jordan Goodman (ed.), Tobacco in History and Culture, Vol. 1, Charles Scribner \& Sons, USA, 2005, pp. 277-81

Masayuki Handa, Tabako Omosiro Igai-shi (The Interesting History of Tobacco), Bungei Shunju Co., Japan, 2002.

B. T. Suzuki, Kitsu'en Denraishi no Kenkyu (A Historical Study of Smoking Introduction into Japan), Shibunkaku Shuppan, Japan, 1999.

Ugata Tamekichi, 'Tabako Bunka-shi', Toho Syo-bo, Japan, 1981.

Tobacco and Salt Museum, 'TOBACCO \& SALT MUSEUM, Japan, 2007. [Museum Guide] 


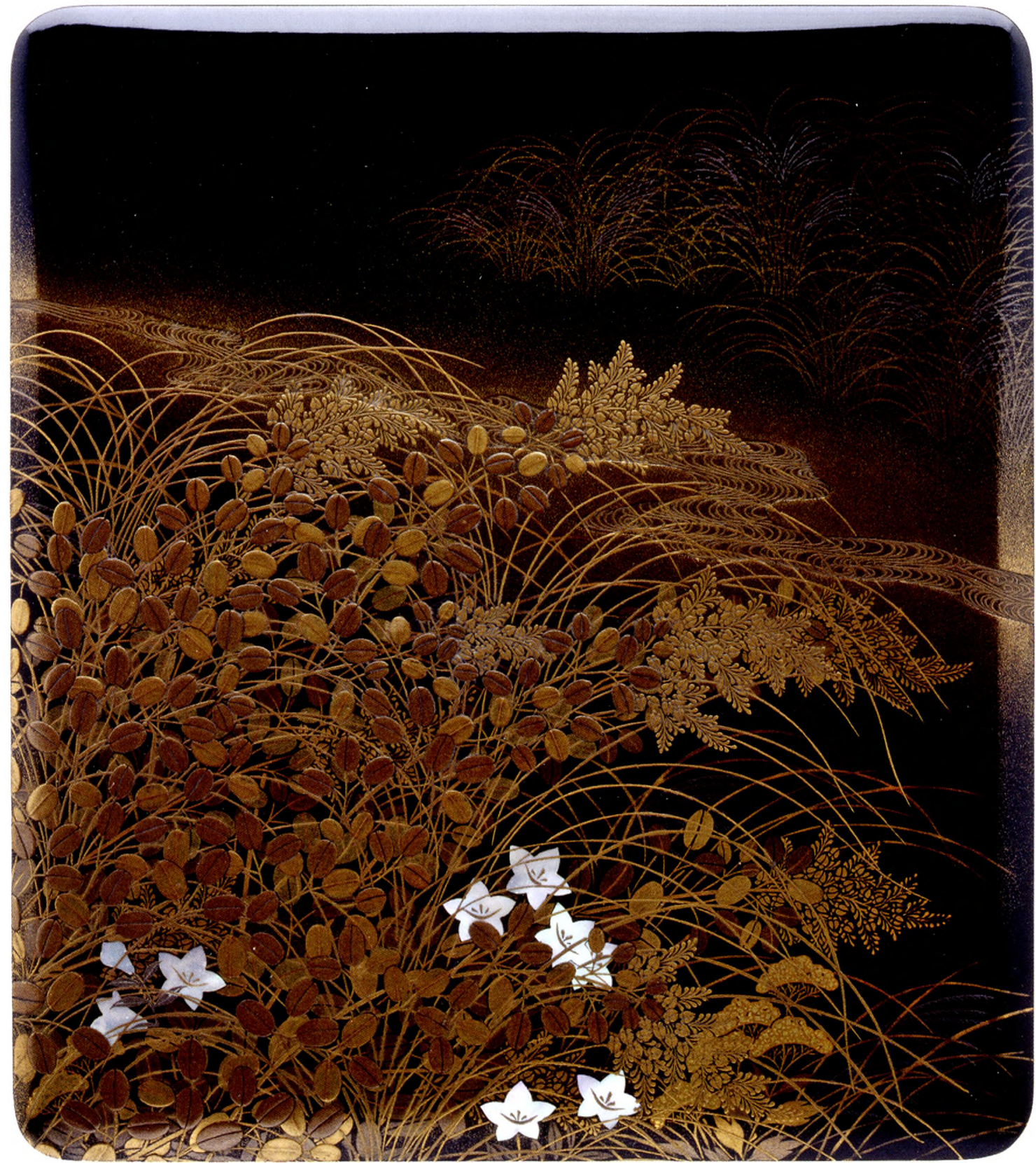

Afb. 1

Buitenaanzicht van de schrijfdoos

Herfstplanten, $19,4 \times 17,3 \times 4,4 \mathrm{~cm}$.

Japan, ca. 1920, Rijksmuseum,

Amsterdam, inv.n. AK-C-2012-2,

bruikleen van Jan Dees en

René van der Star. 